\title{
Polidez em Revista
}

Carolina Scali Abritta

Victoria Wilson

Editoras do Dossiê

Há mais de trinta anos, surgia dentro dos estudos da linguagem um trabalho seminal sobre polidez. Era o famoso escrito de autoria de Brown e Levinson (1978), cuja proposta foi lançar um modelo universal que desse conta das estratégias de polidez usadas nas relações interhumanas.

O trabalho não era o primeiro a tratar do fato de que a linguagem, muito além do domínio informacional, tem também um componente relacional, o que é confirmado pela nossa entrevistada - Profa. Sonia Bittencourt Silveira, nesta edição. Então, o que impressiona na teoria Brown e Levinson? Além de sua capacidade didática de apresentação do tema e seu corpo teórico bem fundamentado, a sua influência na área é gritante. Dificilmente se encontra um trabalho que não os cite. Basta dar uma busca no Google para verificar esse fato.

No cenário atual, ao lado do tema da polidez, a questão do uso da impolidez e até mesmo da rudeza vêm ganhando força teórica e analítica. Além disso, os estudos têm cada vez mais destacado a importância do desenvolvimento de pesquisas discursivas contextualmente embasadas, colocando em relevo o papel fundamental do ouvinte na definição, sempre local, do que seria polido/impolido. Por fim, cumpre dizer que são variados os ramos da Linguística que abordam o tema. A pragmática, a Sociolinguística Interacional e até mesmo as análises do discurso de linha francesa, são algumas das áreas que desenvolvem pesquisas acerca da polidez e da impolidez.

A edição atual da revista Soletras procurou abrir espaço para que todas essas linhas de análise pudessem aparecer e dar destaque ao tema, cuja importância parece inegável não só para o desenvolvimento teórico da área, mas também e fundamentalmente para ampliar o entendimento sobre como as relações humanas se (des) constroem.

Nosso ponto de partida foi uma conversa com a linguista Sonia Bittencourt Silveira, professora aposentada do PPG da Universidade Federal de Juiz de Fora. Ela dedicou boa parte de sua carreira acadêmica aos estudos sobre polidez e a um tema correlacionado - a construção de face. Na entrevista que nos foi concedida, a pesquisadora nos dá um panorama geral da área, destacando inclusive a ampliação do campo de estudos da polidez com a

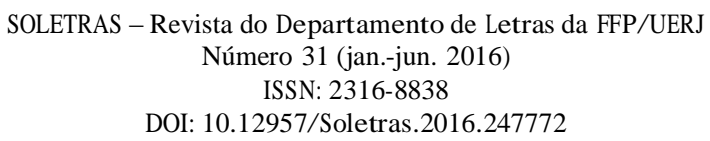


incorporação emancipadora do tema da impolidez. Finaliza a sua fala revelando a importância do tema para pesquisas aplicadas ao ensino.

Os artigos que se seguem à entrevista correspondem predominantemente ao dossiê, seguindo-se a eles uma série de outros relativos a temas ligados ao ensino e à literatura, inseridos em outra seção. Abre o dossiê o artigo "Verbos modais como estratégia linguísticodiscursiva de polidez linguística e preservação de faces nas interações médico-médico e médico-paciente da série House" de Larisse Carvalho de Oliveira, Tiago Alves Nunes e Jorge Luis Queiroz Carvalhos. Nesse artigo, os autores tratam da polidez linguística e dos processos de elaboração de face, com base nos clássicos Brown \& Levinson (1987) e Goffman (1967), além de outros teóricos. Analisam a interação médico-médico e médico-paciente vivida pelos personagens da famosa série de TV House. Os resultados apontaram para a produtividade, na língua inglesa, dos verbos modais, em especial os deônticos, em interações do tipo em que pesam o grau de responsabilidade entre as partes envolvidas (e sua atenuação), as relações de hierarquia e poder e os atos de ameaça à face. Nesse caso, a modalização, como marcador linguístico-discursivo, desempenhou a função pragmática associada à preservação ou à ameaça às faces dos participantes.

O segundo artigo de Nilva Maria Pereira e Ester Maria de Figueiredo Souza, intitulado "Estratégias de cortesia na interação de professora e alunos numa classe de língua portuguesa", focaliza as estratégias de cortesia na interação professor-aluno, em aulas de língua portuguesa, com base nos estudos de Kerbrat-Orecchioni e em conceitos bakhtinianos como o de réplica. No caso da aula analisada, as autoras atribuíram a forte presença de estratégias de cortesia utilizadas pela professora ao tipo de aula (expositiva) e às relações de hierarquia/status social do locutor como forma de minimizar tais relações no ambiente da sala de aula, no momento da interação professor-aluno. Também concluíram com o estudo que as estratégias de cortesia variam conforme o contexto e os grupos culturais e que podem ser ensinadas na escola sob a perspectiva discursiva e pragmática da língua.

Josilene de Jesus Mendonça e Raquel Meister Ko. Freitag, no artigo "Primeira pessoa do plural com referência genérica e a polidez linguística", exploram a indeterminação do sujeito, associando-a ao comportamento polido em termos linguísticos. A análise de fenômenos variáveis, em perspectiva microetnográfica, possibilitou, segundo as autoras, uma visão mais ampliada dos bancos de dados trabalhados. Foram controladas as seguintes variáveis pragmáticas, considerando-se as interações sociais: distância social, relações de poder e grau do custo da imposição. Na análise dos falares sergipanos, foi encontrada a

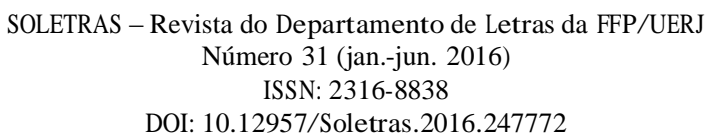


evidência de que a forma "a gente" foi a mais frequente em interações com menor grau de familiaridade entre os interlocutores, em relação à sua variante "nós". Esses dados confirmam a hipótese das autoras de que a forma "a gente" apresenta maior incidência de uso como recurso de indeterminação do sujeito em situações em que o falante não tem o domínio do tópico conversacional, mesmo em contextos mais polidos e com alto grau de imposição. As formas de $1^{a}$ pessoa do plural com referência genérica exercem também um papel discursivo importante como recurso de polidez na manutenção do equilíbrio das relações humanas.

Já o fenômeno da impolidez é explicitado por Marcos Roberto dos Santos Amaral, em seu artigo "A impolidez como princípio constitutivo dos jogos de linguagem: o sentido parcial e violentamente com-partilhado". Sua pesquisa problematiza o princípio de cooperação griceano, voltado para a construção ideal (izada) das relações humanas que seriam pautadas pelo equilíbrio e harmonia, para desconstruir a ideia de simetria das relações de poder que configuram tais relações. $\mathrm{O}$ autor explora diferentes correntes teóricas, na análise online de um blog e um comentador e toda a polêmica gerada a respeito do uso de uma expressão impolida atribuída ao ex-presidente Lula. Ao fim ao cabo, os resultados da análise apontam para a produtividade da impolidez como um fenômeno recorrente nas interações verbais, revisando, científica e ideologicamente, os princípios cooperativos considerados basilares e constitutivos das interações sociais humanas. Segundo o autor, “(...) revisar princípios tradicionais ideológicos linguísticos como os semântico-formais no corpo do princípio da cooperação é passo essencial da consolidação do caráter político dos estudos críticos da linguagem".

$\mathrm{Na}$ linha da descortesia, Ione Vier Dalinghaus, analisa, à luz da semiótica francesa, a força da persuasão em um debate político televisivo em "Estudo da descortesia como estratégia de persuasão em um debate político entre José Serra e Fernando Haddad". No debate em análise, a provocação foi o recurso de manipulação mais empregado pelos candidatos, na tentativa de "derrubar" o adversário, colocando-se em risco as suas respectivas imagens sociais públicas. Os candidatos políticos, nos debates, não hesitam em expressar a descortesia (que pode aparecer dissimulada ou não) quando buscam a autovalorização, pois os efeitos de sentido estão voltados para a desvalorização ou desconstrução da imagem do destinatário e, tem por consequência, o enaltecimento da imagem positiva do locutor, conforme argumenta o autor. Portanto, "o êxito ou o fracasso dos candidatos dependem de como é articulada essa manipulação". Por fim, os resultados dão destaque para a função discursiva da provocação como estratégia discursiva de manipulação e persuasão dos políticos

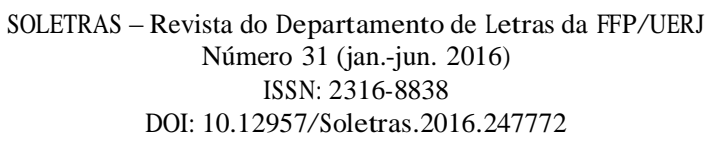


em que o fenômeno da descortesia não só cumpre importante função no debate político como contribui para o fortalecimento de um novo campo de estudos no quadro da teoria geral do discurso, especialmente na Semiótica Discursiva da Linha Francesa.

$\mathrm{Na}$ seção Vária, encontram-se os demais artigos subdivididos em temas ligados ao ensino ou a tópicos dedicados aos estudos literários.

Assim, no artigo de Bruno Defilippo Horta e Priscila Fernandes Sant'Anna, intitulado "A importância do moderador para a educação da oralidade: uma proposta de sequência didática com o gênero debate público regrado", os autores se alinham aos estudos da interação e aos trabalhos dos gêneros baseados em Marcuschi e nas sequências didáticas de Dolz e Scheneuwly. Defendem que o debate público em sala de aula é um gênero propício ao trabalho com a oralidade para o "aperfeiçoamento das competências sócio-comunicativas" do aluno, em contexto formal de uso da língua, adquirindo valor fundamental quando se instala a figura do moderador para atuar em situações de conflito. Nesse caso, a contribuição teórica desse estudo reside não só no trabalho com os gêneros e as sequências didáticas, mas com a oralidade e a gerência do comportamento e das atitudes dos alunos em situações desfavoráveis.

Em "Tecnologias de Comunicação e Informação (TIC): crianças surdas aprendendo a escrever em Língua Portuguesa", Anatália Dejane Silva de Oliveira, Andréa Direne da Matta Castro e Eliata Silva Barros fazem um relato de experiência com base em uma atividade de ensino de língua portuguesa com 30 crianças surdas de uma escola pública para trabalhar o emprego de artigos, elos coesivos e preposições na produção textual escrita dessas crianças com a utilização de recursos midiáticos cuja culminância foi a produção de um livro de histórias.

Osiel Costa Oliveira, em "O ensino de vocabulário em língua inglesa no livro didático "WAY to GO!", propõe atividades didáticas para o ensino do vocabulário mediadas pelo trabalho com os gêneros textuais, associadas a atividades de compreensão oral e escrita devidamente contextualizadas em uma turma do Ensino Médio de uma escola pública. O autor explora o campo da teoria lexical e argumenta sobre a importância da aquisição e ampliação do vocabulário em língua inglesa.

Já é tradição de nossa revista tratar a linguagem com um fenômeno multifacetado e, por isso mesmo, não distinguir de maneira estanque estudos de língua/linguagem daqueles de literatura. A proposta não é construir muros, mas pontes de conhecimento entre conhecimentos. Assim, Renata Quintela Oliveira, no artigo "O afastamento do humano: 
isolamento, imobilidade e a relação homem-máquina. Uma leitura de A Máquina de Joseph Walser", propõe-se a estabelecer um diálogo entre as reflexões da filósofa Hanah Arendt e a obra literária de Walser. Em sua análise, mostra como o autor constrói a desumanização de um personagem através da maneira com que se dá a sua relação com a máquina. Uma relação que beira o autoritarismo próprio de regimes totalitários. Em “Os tempos das piracemas: diálogo entre Ecocrítica e Pós-Colonialismo", Francisco Neto Pereira Pinto e Hilda Gomes Dutra Magalhães estabelecem uma análise do descompasso temporal entre a obra literária em questão e a legislação ambiental pertinente. Por fim, "Imaginário da literatura, o 'bem-amado' migrante", Felipe Freitag coloca em discussão a questão da existência de uma só cultura ou de culturas a partir da análise de uma telenovela brasileira.

Esperamos que as discussões e diálogos aqui propostos possam levar a um entendimento cada vez mais profundo acerca das bases sobre as quais se constroem as relações humanas nos mais diversos contextos em que se manifestam. 